\title{
A Preliminary Study of Energy Recovery in Vehicles by Using Regenerative Magnetic Shock Absorbers
}

R. B. Goldner and P. Zerigian

Tufts Univ., Dept of EECS

J. R. Hull

Argonne National Laboratory 
SAE routinely stocks printed papers for a period of three years following date of publication. Direct your orders to SAE Customer Sales and Satisfaction Department.

Quantity reprint rates can be obtained from the Customer Sales and Satisfaction Department.

To request permission to reprint a technical paper or permission to use copyrighted SAE publications in other works, contact the SAE Publications Group.

This article was prepared as an account of work sponsored by an agency of the United States

Government. Neither the United States Government nor any agency thereof, nor any of their employees, makes any warranty, express or implied, or assumes any legal liability or responsibility for the accuracy, completeness, or usefulness of any information, apparatus, product, or process disclosed, or represents that its use would not infringe privately owned rights. Reference herein to any specific commercial product, process, or service by trade name, trademark, manufacturer, or otherwise does not necessarily constitute or imply its endorsement, recommendation, or favoring by the United States Government or any agency thereof. The views and opinions of authors expressed herein do not necessarily state or reflect those of the United States Government or any agency thereof.

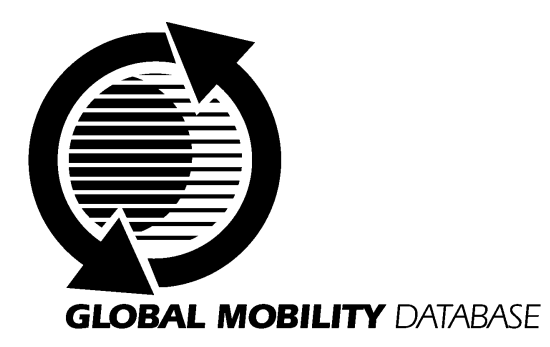

All SAE papers, standards, and selected books are abstracted and indexed in the Global Mobility Database

ISSN 0148-7191

No copyright is asserted in the works of U.S. Government employees.

Positions and opinions advanced in this paper are those of the author(s) and not necessarily those of SAE. The author is solely responsible for the content of the paper. A process is available by which discussions will be printed with the paper if it is published in SAE Transactions. For permission to publish this paper in full or in part, contact the SAE Publications Group.

Persons wishing to submit papers to be considered for presentation or publication through SAE should send the manuscript or a 300 word abstract of a proposed manuscript to: Secretary, Engineering Meetings Board, SAE.

\section{Printed in USA}




\title{
A Preliminary Study of Energy Recovery in Vehicles by Using Regenerative Magnetic Shock Absorbers
}

\author{
R. B. Goldner and P. Zerigian \\ Tufts Univ., Dept of EECS \\ J. R. Hull \\ Argonne National Laboratory
}

No copyright is asserted in the works of U.S. Government employees.

\begin{abstract}
Road vehicles can expend a significant amount of energy in undesirable vertical motions that are induced by road bumps, and much of that is dissipated in conventional shock absorbers as they dampen the vertical motions.

Presented in this paper are some of the results of a study aimed at determining the effectiveness of efficiently transforming that energy into electrical power by using optimally designed regenerative electromagnetic shock absorbers. In turn, the electrical power can be used to recharge batteries or other efficient energy storage devices (e.g., flywheels) rather than be dissipated. The results of the study are encouraging - they suggest that a significant amount of the vertical motion energy can be recovered and stored.
\end{abstract}

\section{INTRODUCTION}

We have been carrying out a proof-of-concept study to evaluate the feasibility of obtaining significant energy savings by using optimized regenerative magnetic shock absorber in vehicles. In addition to other potential applications, the use of such shock absorbers might allow for improved energy efficiency in electrical vehicles through the conversion of otherwise parasitic mechanical power losses into stored electrical energy, thereby leading to longer distances between battery recharges.

We recently carried out two experiments that validated a simplified eddy current damping model which, together with a "road bump" model (discussed further below), has been used to estimate the average power/energy recovery that might accrue for a $2500 \mathrm{lb}$ automobile travelling on a "typical" road in the United States. The estimates are summarized in Table 1, and suggest that with a set of optimized regenerative shock absorbers, the average vehicle on the average road driving at 45 mph might be able to recover up to $70 \%$ of the power that is needed for such a vehicle to travel on a smooth road at $45 \mathrm{mph}$; and, therefore, for an electrical vehicle with regenerative brakes and with the regenerative shock absorbers recharging the vehicle's battery, the effective "charge mileage" might be significantly increased

Presented in the Appendices are discussions of the simplified eddy current damping and road bump models. Presented below are the results of the two experiments used to validate the eddy current damping model, a further discussion of Table 1, including a discussion of the assumptions used to generate the table, and a brief description of planned experiments that will be used to obtain a more accurate road model.

\section{TWO EXPERIMENTS USED TO VALIDATE A SIMPLIFIED EDDY CURRENT DAMPING MODEL}

Presented in Appendix $A$ are the equations for the simplified eddy current damping model. These equations were used to predict the results of a transit time experiment and of an electrical generator (voltage generation) experiment, thereby validating the applicability of the model. This, in turn, has provided us with the confidence needed to employ the model to assess the potential power recovery that one can attain from such shock absorbers used by vehicles as they travel on a typical U.S. highway.

2.1 TRANSIT TIME EXPERIMENT - The equations in Appendix $A$ can be used to estimate the time for a cylindrical rod magnet, of mass, $\mathrm{m}$, which is dropped through a vertically-oriented copper tube, to transit the length of the tube. Figure 1 illustrates the parameters involved in the experiment. In particular, the transit (or delay) time, $t_{d}$, is very nearly $L_{\text {tube }} / v_{\text {terminal }}=L_{\text {tube }} / g \tau=L_{\text {tube }}$ $\gamma /(\mathrm{mg})=\left(\mathrm{L}_{\text {tube }}\right)(2)\left(\sigma_{\mathrm{Cu}}\right)\left(<\mathrm{B}_{\mathrm{r}}^{2}>\right)\left(\mathrm{vol}_{\text {coil }}\right) /(\mathrm{mg})$. For the experiment we carried out, $\mathrm{m} \approx 30$ grams, $\mathrm{L}_{\text {tube }} \approx 100 \mathrm{~cm}$, $\sigma_{\mathrm{Cu}} \approx 5 \times 10^{5} \mathrm{~S} / \mathrm{cm},(\mathrm{vol})_{\text {Cu tube }} \approx 2.82 \times 10^{-7} \mathrm{~m}^{3}(\mathrm{~h} \approx 6 \mathrm{~mm})$ and $\left\langle\mathrm{B}_{\mathrm{r}}^{2}\right\rangle \approx(0.29 \mathrm{~T})^{2}$. (The factor of two is to account for 
double damping arising from the two poles of the magnet.) Using $g=9.8 \mathrm{~m} / \mathrm{s}^{2}$, this yields, $\mathrm{t}_{\mathrm{d}} \approx 8.0$ seconds, which is in good agreement with the measured transit time, $(8.0 \pm 0.5 \mathrm{~s})$, using a stop watch.

Table 1. Estimated regenerated power ( $P_{\text {regen }}$, watts) or fraction recovered $\left(\eta_{20}\right)=P_{\text {regen }} /\left(P_{\text {regen }}+P_{\text {dissipated }}\right)$ as a function of bump height ( $h, \mathrm{~mm})$ and effective baselength width, $\mathrm{w}_{\mathrm{e}}$, (or slope, $\mathrm{m}=2 \mathrm{~h} / \mathrm{w}_{\mathrm{e}}$ ). $\mathrm{P}_{\text {dissipated }}=$ power required to maintain a 2500 pounds (plus mass of 4 shock absorbers) vehicle moving with an average speed of $20 \mathrm{~m} / \mathrm{s}$ (45 mph) on a smooth (bump-free) road $\left.\approx 7500 \mathrm{~W}^{*+*} .<\left|\mathrm{v}_{\mathrm{z}}\right|\right\rangle=$ vertical velocity average magnitude.

\begin{tabular}{|c|c|c|c|c|}
\hline $\begin{array}{c}\mathrm{H} \\
(\mathrm{mm})\end{array}$ & $\mathrm{m}^{*}$ & $\begin{array}{c}<\left|\mathrm{v}_{\mathrm{z}}\right|> \\
(\mathrm{m} / \mathrm{s})^{* *}\end{array}$ & $\begin{array}{c}\mathrm{P}_{\text {reaenerated }} \\
(\mathrm{W})\end{array}$ & $\begin{array}{c}\eta_{20} \\
(\%)\end{array}$ \\
\hline 1 & 0.01 & 0.2 & 1915 & 20 \\
\hline 1.5 & 0.015 & 0.3 & 4340 & 37 \\
\hline 2 & 0.02 & 0.4 & 7730 & 51 \\
\hline 2.5 & 0.025 & 0.5 & 12180 & 62 \\
\hline 3.0 & 0.03 & 0.6 & 17400 & 70 \\
\hline
\end{tabular}

"Calculated for effective baselength width, $\mathrm{w}_{\mathrm{e}}=20 \mathrm{~cm}$. $\left(\mathrm{w}_{\mathrm{e}} / 2=10 \mathrm{~cm}\right)$.

${ }^{* *}$ Calculated for a horizontal speed of $\left\langle\left|v_{x}\right|\right\rangle=20 \mathrm{~m} / \mathrm{s}$ (or $45 \mathrm{mph}$ ).

${ }^{* *}$ Calculated using $\mathrm{P}_{\text {dissipated }}=7500 \mathrm{~W} \approx$ power needed to maintain $20 \mathrm{~m} / \mathrm{s}$ (45 mph) for $2500 \mathrm{lb}$ vehicle + added mass of shock absorbers on a smooth (bump-free) road..

Estimated using data from Reference [2] - (General Motors Impact (electrical vehicle) specifications; and from H. C. Wolfe, senior editor, "Efficient Use of Energy", Chap. 4, AIP Conference Proceedings No. 25, American Institute of Physics, NY (1975).

\subsection{ELECTRICAL GENERATOR EXPERIMENT - TO} further test the model, we set up a periodic road bump simulator test stand, as shown in the photograph of Figure 1. This was in the form of a grinder that had one of its grinding wheels replaced by an aluminum disk which had a rounded, adjustable height, "bump." This is illustrated in Figure 2, which is a schematic of the test stand with a (non-optimized) model magnetic shock absorber. Shown in Figure 2 is a permanent magnet, (a 0.5 " diameter x 1.25" neodymium( $\mathrm{Nd}$ )-iron( $\mathrm{Fe}$ )-boron(B) magnet kindly donated by Crucible Magnets), whose radial magnetic flux density map $\left[\mathrm{B}_{r}(r, z)\right]$ is shown in Figure 3 . The height of the bump, h, could be adjusted from that of a smooth road $(h=0)$ to that of a "very bumpy" road ( $\mathrm{h}>5 \mathrm{~mm}$. For the experiment reported herein, h was set to $2 \mathrm{~mm}$. After randomly sampling road profile data from all 50 states (discussed further below), we believe $\mathrm{h}=2 \mathrm{~mm}$ is close to what might be the typical U.S. highway bump height.

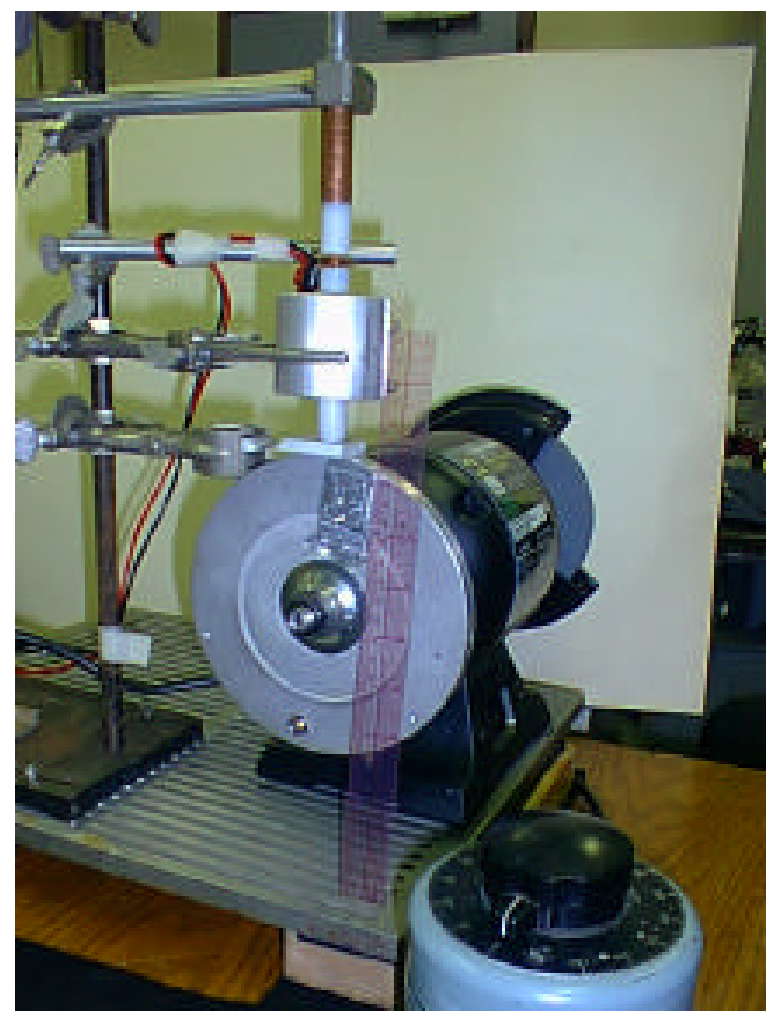

Figure 1. Photograph of test setup to evaluate electrical model of regenerative magnetic shock absorber.

Concentric with the magnet was a Teflon tube and a 110 turn copper wire (AWG\#34, .006" diam.) coil the dimensions of which are approximately: coil diameter = $15 \mathrm{~mm}$, cross section $=3 \mathrm{~mm}$ high by $0.6 \mathrm{~mm}$ in radial direction. Also contained in the Teflon tube were two Teflon push rods - one above and one below the magnet - as well as a stiff spring at the top of the "piston", and the spring was restrained from moving above a restrainer, as indicated in Figure 2. The bottom Teflon rod was rounded at its lower end, and the rounded nose loosely fit into a concave cut out in a flexible 1/8" thick Teflon plate that was cantilevered at one end. This allowed the plate, (and, therefore, the "piston"), to be pushed up by a rotating controlled-height "bump" (mounted on a rotating 6.5 " diameter aluminum wheel that replaced one of the grinding wheels of a commercial $1 / 2 \mathrm{hp}$ shop grinder), and pushed down by the upper constrained spring. The entire assembly was clamped to a laboratory ring stand, which was tightly clamped to a slotted aluminum servo test bed. The test bed, in turn, was clamped to a cushioned wooden table top (as shown in the photograph of Figure 4). The output voltage from the coil was measured with an oscilloscope, also shown in Figure 4. The oscilloscope traces were photographed with a digital camera, and one is shown in Figure 5. 


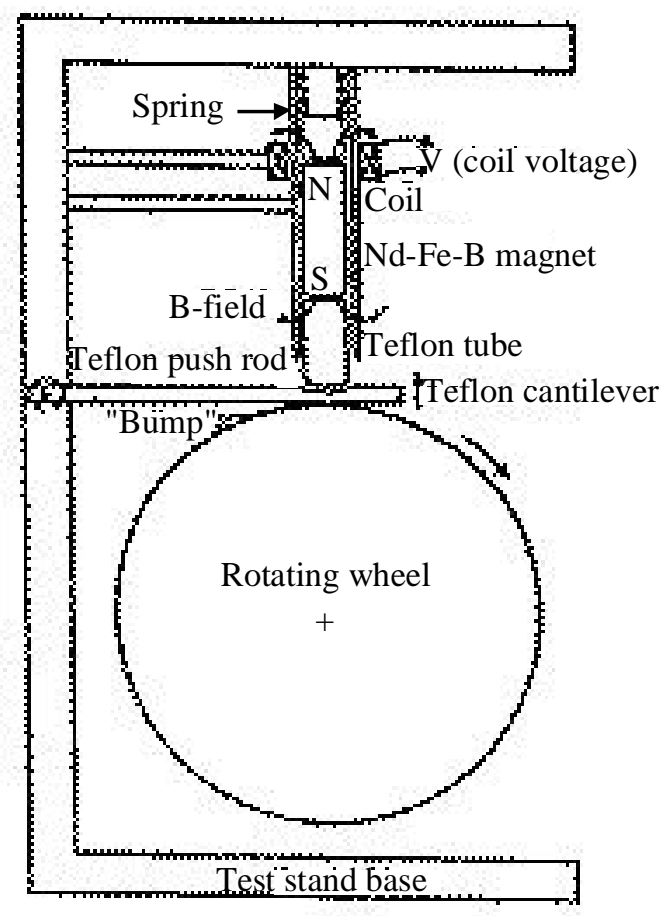

Figure 2. Schematic of test stand setup for experimental validation of electrical model for regenerative magnetic shock absorber.

\subsection{DISCUSSION OF RESULTS OF ELECTRICAL} GENERATOR EXPERIMENT - As seen in Figure 5, the peak voltage was approximately 1.3 volts when the vertical velocity, $v_{z}$, was approximately $1.1 \mathrm{~m} / \mathrm{s}$. This corresponds to a tangential velocity of $2 \pi f R=10 \mathrm{~m} / \mathrm{s}$ for a rotation frequency $f=20 \mathrm{~Hz}$, and a wheel radius, $R=$ $80 \mathrm{~mm}$ (3.187"), and a "bump" height = $2 \mathrm{~mm}$ and width = $15 \mathrm{~mm}$. For these dimensions and the geometry of the test setup the "short" bump model best applies (cf. below for a discussion of the short and long bump models). Using equation (2) for the generated voltage, and replacing $\left(N_{w} \pi d_{c}\right)$ by the length of the coil, $L=5.2 \mathrm{~m}$, one predicts that the average radial magnetic flux density, $\left\langle B_{r}\right\rangle=B_{0}$, over the volume of the coil should have been approximately $2.3 \mathrm{kG}(0.23 \mathrm{~T})$. This is in good agreement with the field map of Figure 3 , where one can observe that for the radial distance from the magnet outer surface $r \approx 0.5 \mathrm{~mm}$ and for the region $\approx 1.5 \mathrm{~mm}$ on either side of the magnet edge (where $B_{r}$ peaks) the average for $B_{r}$ is between 2 and $2.5 \mathrm{kG}$. Thus, we argue, these results also validate the eddy current damping model.

It should be noted that because the "bump" was actually rounded, rather than having a sharp apex, one expects a relatively rapid (in time), but quite finite, initial rise (and final fall) in the voltage. Such was the case, as seen in Figure 5. In the next section, (where we discuss a road model), the case of a sharp (i.e., triangular) bump is discussed and a very rapid rise (and return) in the voltage is predicted.]

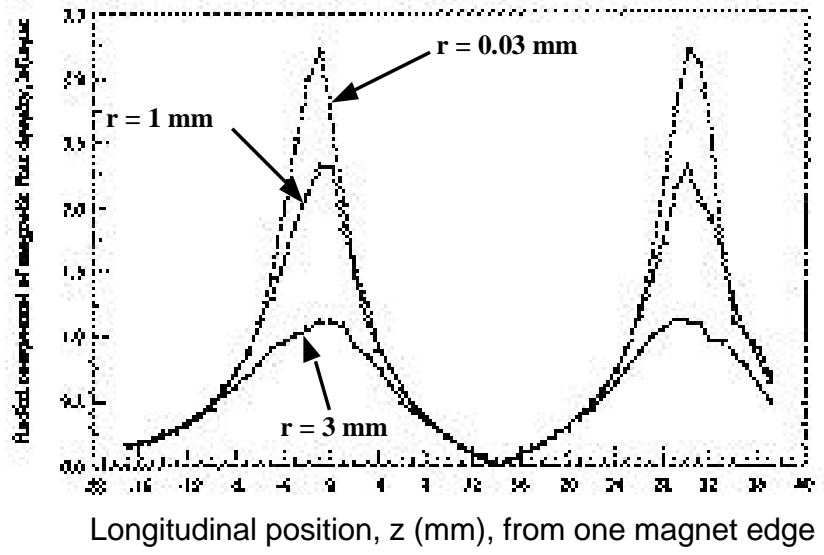

Figure 3. Radial component of the magnetic flux density for $\mathrm{Nd}-\mathrm{Fe}-\mathrm{B}$ permanent magnet as a function of radial position, $r(\mathrm{~mm})$, from magnet surface and the longitudinal position, z $(\mathrm{mm})$, from one edge (pole)

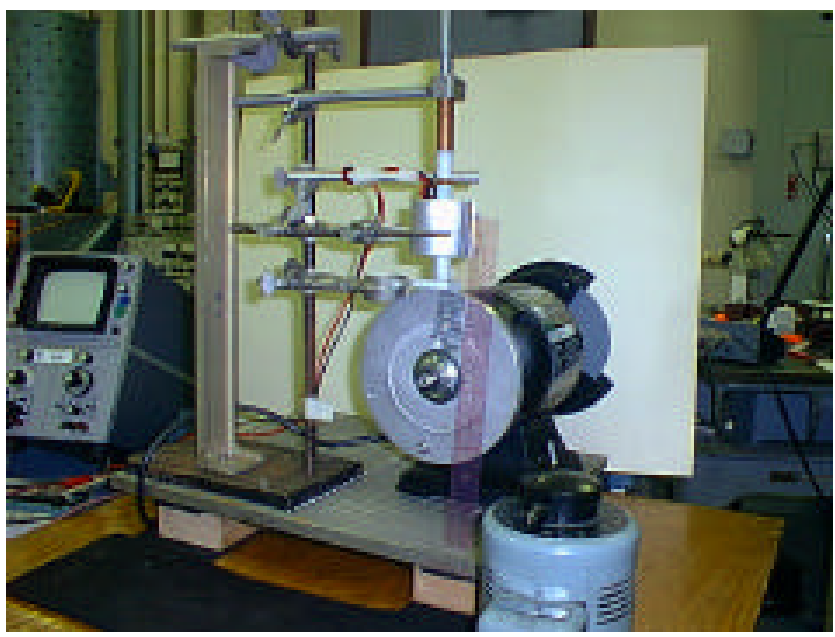

Figure 4. Assembly for validating electrical model of regenerative magnetic shock absorber.

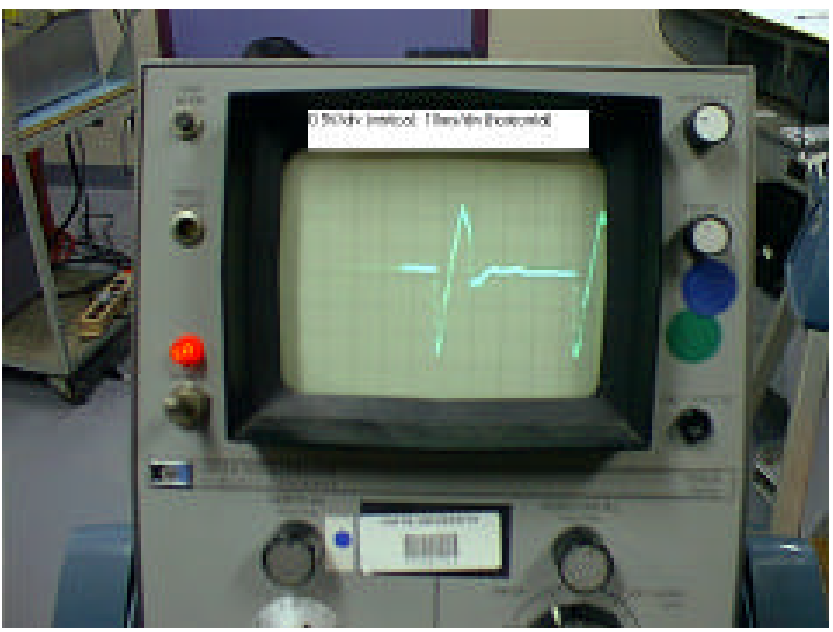

Figure 5. Oscilloscope trace of voltage generated from test setup of Figs. 1 and 2 . The peak voltage is approximately -1.3 volts, and the repetition frequency is approximately $20 \mathrm{~Hz}$ (i.e., the period is approximately $50 \mathrm{~ms})$. 
Given that the two experiments described above served to validate the simplified eddy current model, to estimate the otherwise wasted power that might be recovered by a $2500 \mathrm{lb}$ automobile travelling at $45 \mathrm{mph}(20 \mathrm{~m} / \mathrm{s})$ on a "typical" U.S. highway, the remaining task was to model the "typical" U.S. highway or, alternatively, to estimate the "average vertical velocity, $\left\langle\left|\mathrm{v}_{\mathrm{z}}\right|\right\rangle$ " in the regenerative power equation (A11). Hence the road model of Appendix $B$ was developed which, in turn, was used with available road profile data to estimate $\left\langle\left|v_{z}\right|\right\rangle$.

\subsection{USE OF ROAD PROFILING DATA TO ESTIMATE} $<\left|V_{z}\right|>$ AND \% POWER/ENERGY RECOVERY - In order to estimate the likely range of vertical velocity magnitudes, $\left|\mathrm{v}_{\mathrm{z}}\right|$, and therefore the likely range of recoverable power, we turned to road profile data (cf. Figure B2 for a road profile of one section of a Massachusetts highway) which were obtained for all the states in the U.S.. These data are part of a 20 year Federal Highway Administration Long Term Pavement Performance (LTPP) study. The compilation began in 1989 and is available from a University of Michigan website [1]. Unfortunately, the data has been low pass filtered (although the profiles were collected with a 2.5 $\mathrm{cm}$ sample interval, a moving average was computed for 12 such points and reported every $15 \mathrm{~cm}$ [2], eliminating wavelengths shorter than $30 \mathrm{~cm}$ - note that the data points in Figs. B2 (b), (c) and (d), occur only every $15 \mathrm{~cm}$ [2]). Also some of the early data were obtained for freshly repaved roads [2]. Therefore, although we could obtain averages directly from the data (e.g., we could obtain average bump slope magnitudes by simply summing the magnitudes of differences in adjacent elevations and dividing by $15 \mathrm{~cm}$ ), we concluded that it would only yield a lower bound for $\mathrm{v}_{\mathrm{z}}$. This was done for the first 104 meters of the data of Figure B2, and the average slope was approximately 0.005 . Multiplying this by $20 \mathrm{~m} / \mathrm{s}$ (which was assumed to be close to the average vehicle speed in the U.S.), yielded a lower bound estimate for $\left.<\left|v_{\mathrm{z}}\right|\right\rangle_{\text {min }} \approx 0.1 \mathrm{~m} / \mathrm{s}$. Since this assumes the highest frequency is $1 / 30 \mathrm{~cm}^{-1}$, if one makes the reasonable approximation that the mean slope might be double or more, (due to higher frequencies that were undoubtedly present, but were not accounted for by the manner in which the data were recorded), would imply that $\left\langle\left|\mathrm{v}_{\mathrm{z}}\right|\right\rangle \geq$ $0.2 \mathrm{~m} / \mathrm{s}$.

After analyzing several other road profiles, we estimated that there is a range of bump heights, $1 \mathrm{~mm} \leq \mathrm{h} \leq 3 \mathrm{~mm}$, which appears to be representative of many roads, with corresponding slope magnitudes, $0.010 \leq|\mathrm{m}| \leq 0.030$ (assuming a spatial frequency of approximately $10 \mathrm{~cm}^{-1}$ ). Thus, for an average horizontal speed of $20 \mathrm{~m} / \mathrm{s}$ (45 $\mathrm{mph}$ ), there results a range of vertical velocity magnitudes of: $0.2 \mathrm{~m} / \mathrm{s} \leq\left|\mathrm{v}_{\mathrm{z}}\right| \leq 0.6 \mathrm{~m} / \mathrm{s}$. This, in turn, translates into a range of likely regenerated powers: 1.92 $\mathrm{kW} \leq \mathrm{P}_{\text {regen }} \leq 17.24 \mathrm{~kW}$ and an associated likely range for percentage of recovered power (or energy): namely, $20 \% \leq \eta_{20} \leq 70 \%$. This is summarized in Table 1 .
To determine the truth of these attractive estimates, the Department of Energy has initiated a joint project between Tufts University and Argonne National Laboratory in which we are now engaged. The project involves designing and constructing (non-optimized) test model regenerative magnetic shock absorbers which are to be installed on an instrumented small offroad vehicle. Two experiments will be made on the vehicle: (i) testing the power output from the shock absorbers with the vehicle mounted on a programmable shaker table; and (ii) testing the power output from the shock absorbers while the vehicle is driving on roads in the vicinity of Argonne National Laboratory. A related set of experiments, on only a shock absorber, will be carried out at Tufts University. In this manner, we anticipate obtaining a more accurate road model (as well as a more accurate shock absorber model) and, therefore, a more accurate assessment of the potential utility of regenerative magnetic shock absorbers for power/energy recovery.

\section{CONCLUSIONS}

It is clear that the missing link in our analysis is an accurate road model, which we anticipate rectifying soon with test model regenerative magnetic shock absorbers mounted on an instrumented test vehicle as well as shaker table testing an isolated test model regenerative magnetic shock absorber. However, using road profile data, together with two models [(i) a validated eddy current damping model (Appendix A), and (ii) a (yet to be validated) road model (Appendix B)], we have been able to estimate that the range for the percentage of recoverable power/energy for a $2500 \mathrm{lb}$ vehicle that employs four optimized design regenerative magnetic shock absorbers and whose average speed is 20 meters/s ( $45 \mathrm{mph}$ ) on a typical U.S. highway is likely to be between $20 \%$ and $70 \%$. This result indicates that, with regenerative brakes and regenerative magnetic shock absorbers, electric vehicles might have significantly improved "charge-mileage". Clearly, this would be a desirable result, especially if the shock absorbers could be manufactured economically.

\section{ACKNOWLEDGMENTS}

The authors would like to gratefully acknowledge assistance from a former Tufts undergraduate student Scott Frey; useful discussions with Paul Kelley and Robert Guertin of Tufts University; and assistance from Steve Karamihas of the $U$. of Michigan in obtaining and understanding road profiles; and they are especially grateful for the enthusiastic support and encouragement received from Sid Diamond of the Department of Energy. This work has been supported in part by the Department of Energy, Office of Heavy Vehicle Technologies and Advanced Automotive Technologies, under Contract W31-109-Eng-38; and by private donations from Frank and Eleanor Pao. 


\section{REFERENCES}

1. U.S. Dept. of Transportation, Federal Highway Administration, Long-Term Pavement Performance Program, (http://www.tfhrc.gov/pavement/ltpp/ resource.htm); also (http://www.tfhrc.gov/pavement/ Itpp/data.htm); and another website which has some of the LTPP data in a convenient format is at the University of Michigan (http://www.umtri.umich.edu/ erd/roughness/indes.html). Most of the LTPP data are available in DataPave, an easy to use software package that contains LTPP data released as of September 1999. DataPave is available on CD-ROM, free of charge, from the LTPP Customer Service Center, telephone: (865) 481-2967, fax: (865) 4818555, or e-mail: Itppinfo@fhwa.dot.gov.

2. Steve Karamihas, University of Michigan Transportation Research Institute,University of Michigan, private communication (stevemk@umich. edu).

3. Estimated from General Motors Impact (electrical vehicle) specifications; and from Hugh C. Wolfe, senior editor, "Efficient Use of Energy", Chap. 4, AIP Conference Proceedings No.25, American Institute of Physics, NY (1975).

\section{APPENDIX A - SIMPLIFIED EDDY CURRENT DAMPING MODEL FOR PREDICTIONS FOR TWO EXPERIMENTS}

Consider Figure A1, which illustrates the experiment of dropping a cylindrical rod magnet through either copper wire coils, or a relatively long (>> magnet length) copper tube. The Lorentz electric field in the copper wire coil (or in the corresponding region of the copper tube), moving with a relative velocity $v_{z}$ in a radial magnetic field of flux density, $B_{\mathrm{r}}(\mathrm{T})$, is in the $f$-direction (in cylindrical coordinates), and is given by:

$$
E_{\text {Lorentz }}=E_{\phi}=v_{z} B_{r}
$$

The corresponding eddy current density is:

$$
J_{\phi}=\sigma_{C u} E_{\phi}
$$

and the differential eddy current passing through a differential cross-section area, $d A$, is:

$$
d I=J_{\phi} d A
$$

The differential back (or damping) force, on the differential volume $\mathrm{d}(\mathrm{vol})$ is:

$$
\begin{aligned}
\left|d F_{\text {back }}\right| & =\left|d F_{\text {damping }}\right|=d F_{d} \\
& =\left(J_{\phi}\right)\left(B_{r}\right) d\left(\text { vol }_{\text {coil }}\right) \\
& =(\sigma C u)\left(B_{r}{ }^{2}\right) d\left(\text { vol }_{\text {coil }}\right)
\end{aligned}
$$

On integrating, the damping force is:

$$
F_{d} \approx\left[\sigma_{C u}<B_{r}{ }^{2}>\left(v_{\text {ool }} l_{c o i l}\right)\right] v_{z} \equiv[\gamma] v_{z}
$$

Thus, from Newton we have $(g=$ acceleration due to earth's gravity force:

$m_{\text {mag }}\left(\frac{d v_{z}}{d t}\right)=m_{m a g} g-F_{d} \equiv m g-\gamma v_{z}$

Rewriting the last equation yields:

$\frac{d v_{z}}{d t}+\left(\frac{\gamma}{m} \equiv \tau^{-1}\right) v_{z}=g$

Solving, using an initial velocity $=0$,

$v_{z}=\left(v_{\text {terminal }} \equiv v_{T} \equiv g \tau\right)\left(1-e^{-\frac{t}{\tau}}\right)$

The electromotive force $e m f \equiv V e$ can be found from:

$$
V_{e}=\int_{\text {coillength }} E_{\phi} d L_{\text {coil }} \approx\left\langle B_{r}\right\rangle v_{z} L_{\text {coil }}
$$

Likewise, the current, I, can be written as:

$$
I \approx \sigma_{C u}\left\langle B_{r}>v_{z} A_{\text {wire }}\right.
$$

For each coil we can therefore write an expression for the maximum power:

$$
P_{\max } \equiv \frac{V_{e} I}{4} \approx\left(\sigma_{C u}\right)\left(v_{z}^{2}\right)\left(<B_{r}^{2}>\right)\left(v_{o l} l_{\text {coil }}\right) / 4
$$

The coil volume is given by:

$$
\text { vol }_{\text {coil }}=L_{\text {coil }} A_{\text {wire }} \approx \pi\left(r_{\text {inner }}{ }^{2}-r_{\text {inner }}{ }^{2}\right) h .
$$

These equations formed the basis of two validation experiments and, together with road profile data, allow us to estimate the power/energy recovery one might be able to obtain by replacing conventional shock absorbers with optimized regenerative magnetic shock absorbers. 


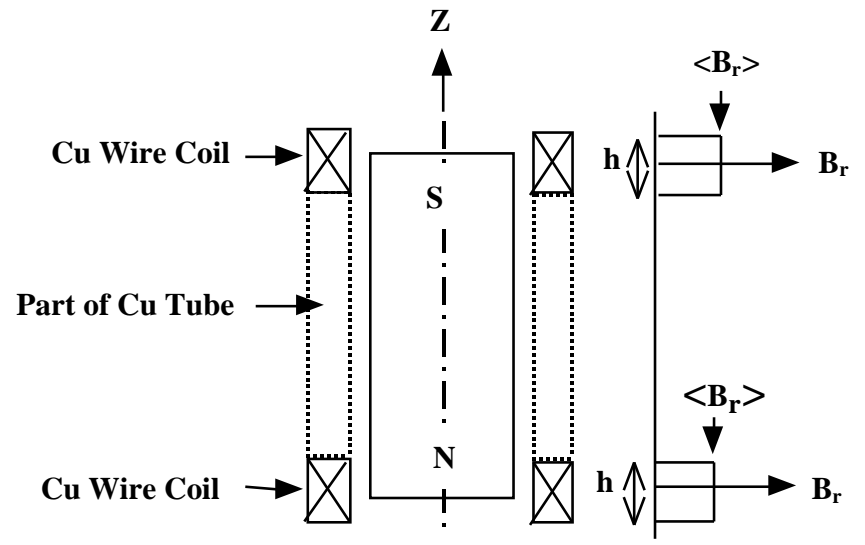

Fig. A1. Setup for verifying simplified eddy-current model. Shown is a cylindrical rod magnet (with its two magnetic poles indicated by $\mathrm{N}$ and $\mathrm{S}$ ) dropping through a copper tube (a part of which is indicated by dashed lines) or a copper wire coil of height $h$ (indicated by a rectangle with a diagonal cross). In the simplified model, the distribution of the radial component of the magnetic flux density, $B_{r}$ (teslas), in the vicinity of either magnetic pole, in the copper coils (of height, $h$ ), or over the same range, $\mathrm{H}$, for the copper tube (considered much longer than a single magnet), is approximated by the distributions shown on the right hand side - i.e., an average, $\left\langle B_{r}\right\rangle$ (over h).

\section{APPENDIX B - ROAD MODEL}

\section{B.1 Model Geometry of a Wheel Riding Over} an Idealized Bump - Shown in Fig. B1 is the model geometry of a wheel (or tire), of radius, $\mathrm{R}$, riding over an idealized bump taken to be an isosceles triangle (shaded area) of height $h(<<R)$, and of base width equal to $2 w$. We shall refer to $z(x)$ as the vertical position of the wheel axle when it is moving in the $+x$ direction, and $x$ is measured with respect to the $x$-position of the center of the triangular bump (i.e., the x-position of the apex of the bump taken to be $x=0$ ). We shall refer to two models, the short bump model and the long bump model.

In terms of Fig. B1, the short bump model applies if b $>$, i.e., the wheel (or tire) first touches the apex of the triangular bump before "climbing" the bump; and the long bump model applies if $b<w$, i.e., the wheel first climbs the bump before touching the apex of the bump. [The $x$-position, $x=-b$ corresponds to where the tangent to the wheel, (at the point where the wheel first touches the apex, as shown in Figure B1 for the short bump case) intersects the negative part of the $x$-axis.] From the geometry of Figure B1 we can write equation (B1) for b:

$b=\frac{h R-h}{\sqrt{2 h R-h^{2}}} \approx \sqrt{\frac{h R}{2}}$, for $h \ll R$.

Likewise, we can write for c:
$c=\sqrt{R^{2}-(R-h)^{2}} \approx \sqrt{2 R h}$ for $h<<R$.

B.2 Short Bump Model for $\mathrm{v}_{7}$ of Eq. (A11) - For the geometry of Figure $B 1$, where the wheel is rotating clockwise, the wheel axis moves with a horizontal velocity, $v_{x}$, and a vertical velocity, $v_{z}$. Any nonzero $v_{z}$ translates directly into a vertical motion of the magnetic shock absorber piston as discussed above, (i.e., the piston's velocity is also $v_{\mathrm{z}}$, the same velocity as in equation (A11)). For the short bump model, we can now derive $v_{z}$ as a function of $v_{x}, R$, and $h \ll R$.

In particular, we may now write, for $\mathrm{x}>\mathrm{c}, \mathrm{z}=\mathrm{R}$, but for $-\mathrm{c}<$ $\mathrm{x}<+\mathrm{C}$ :

$x^{2}+(z-h)^{2}=R^{2}$.

We can also write for $-c \leq x \leq c$, using (B3):

$\frac{d z}{d x}=-\left(\frac{x}{z-h}\right)=-\left(\frac{x}{\sqrt{R^{2}-x^{2}}}\right)$

For $x<R$, we can approximate (B4) by (B5):

$\frac{d z}{d x} \approx-\left(\frac{x}{R}\right)\left[1+\frac{1}{2}\left(\frac{x}{R}\right)^{2}\right] \approx-\left(\frac{x}{R}\right)$.

Note that the derivative is positive for $x<0$, and also that the derivative is equal to the ratio of $v_{z}$ to $v_{x}$; i.e.,

$$
\frac{d z}{d x}=\frac{v_{z}}{v_{x}} \approx-\left(\frac{x}{R}\right) .
$$

This analysis indicates that for $x<-c, v_{z}=0$, but $v_{z}=$ $(\mathrm{c} / \mathrm{R})\left(\mathrm{v}_{\mathrm{x}}\right)$ at $\mathrm{x}=-\mathrm{c}$, and as $\mathrm{x}$ increases it decreases linearly to zero at $x=0$; then as $x$ increases further, its magnitude increases linearly back to $(\mathrm{c} / \mathrm{R})\left(\mathrm{v}_{\mathrm{x}}\right)$ at $\mathrm{x}=+\mathrm{c}$. For $\mathrm{x}>\mathrm{c}$, it returns to zero. Also, from eq. (B6), we may write: $\left\langle\left|v_{z}\right|>\right.$ $\approx(\mathrm{c} / 2 \mathrm{R})\left(\mathrm{v}_{\mathrm{x}}\right)$, for $\mathrm{x} \leq \mathrm{c}$, where $\left\langle\left|\mathrm{v}_{\mathrm{z}}\right|>\right.$ refers to the average value of the magnitude of $\mathrm{v}_{\mathrm{z}}$. (The sign of the velocity is unimportant since we are interested in power regeneration.) Thus, since the voltage generated in the shock absorber is directly proportional to $\mathrm{v}_{\mathrm{z}}$, the very rapid rise (and return) in $\left|v_{z}\right|$ leads to the same behavior for the voltage, as previously mentioned in section 2.3.

It should be pointed out that if the spatial frequency of the bumps is too high, i.e., if the baselength is too short $(<2 c)$, the wheel will bridge neighboring bumps, thereby reducing the amplitude of $z(x)$ and, therefore $\left|v_{z}\right|$.

\section{B.3 Long Bump Model for $\mathbf{v}_{\mathbf{z}}$ of Equation (A11)} - As mentioned above, the long bump model applies for $w>b$ (i.e., the wheel climbs the bump prior to touching the apex of a triangular bump). In this case, $v_{z}$ almost 
immediately rises to, and remains at, $\mathrm{v}_{\mathrm{z}}=(\mathrm{dz} / \mathrm{dx}) \mathrm{v}_{\mathrm{x}}$, where $(\mathrm{dz} / \mathrm{dx})=(\mathrm{h} / \mathrm{w})$, the slope of the bump for $\mathrm{x}<0$; and $\left|\mathrm{v}_{\mathrm{z}}\right|=$ $\mathrm{h} / \mathrm{w}$, for $|\mathrm{x}|<\mathrm{w}$.

Although our experimental conditions (see Sec. 2) are best fit by a short bump model, the road profiles we studied (cf. Sec. 2.4) seem to be best represented by the long bump model.

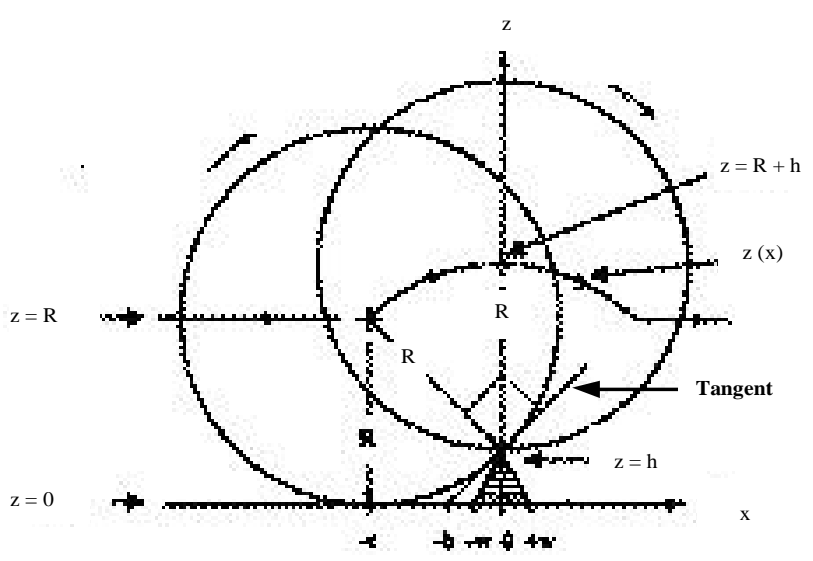

Figure B1. Geometry for road bump models. Shaded triangle $=$ idealized bump, centered at $x=0$, of height $=$ $h$, and width $=2 w$. $R=$ radius of vehicle wheel (or tire). Wheel axle vertical position is $\mathrm{z}(\mathrm{x})$. Two wheel axle horizontal positions are shown (at $x=-c$ and at $x=0$ ).
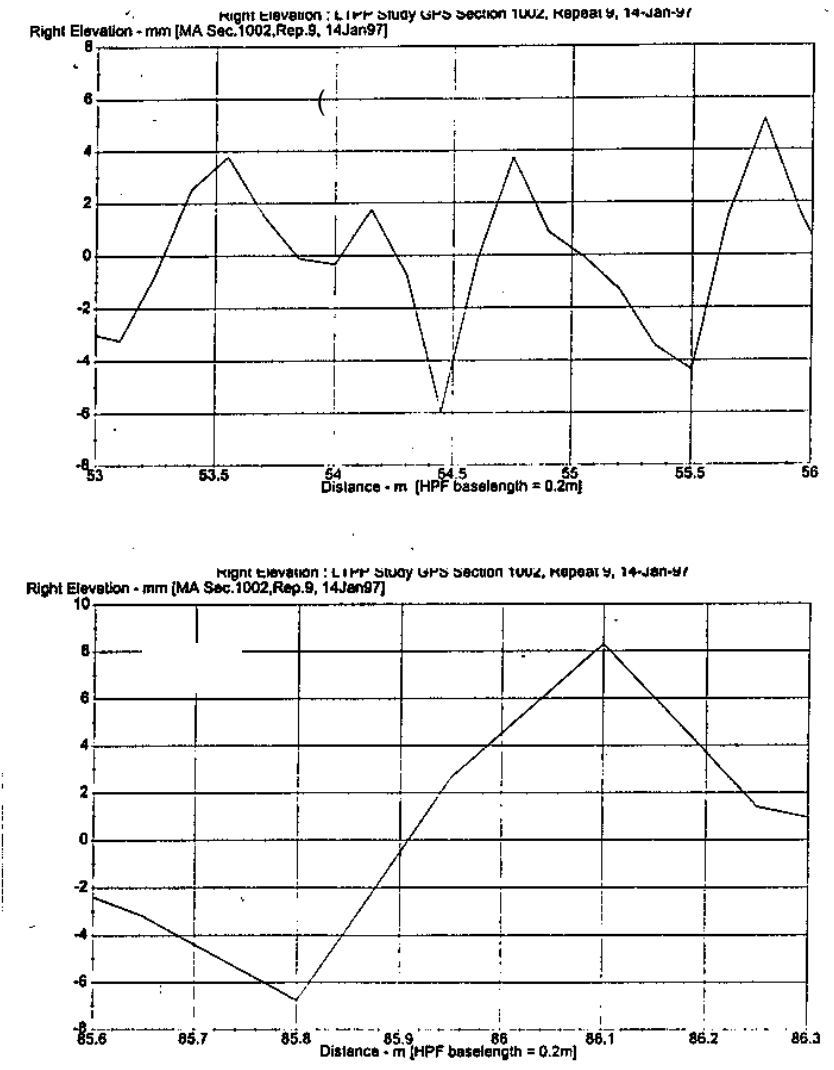

Figure B2. Different portions of a selected road profile from Massachusetts. All portions have been high pass filtered (baselength $=0.2 \mathrm{~m}$ ). Profile was recorded on 14 January 1997. 